\title{
O QUE FALAM OS DISCURSOS DE GESTORES ESCOLARES SOBRE A QUALIDADE EDUCACIONAL
}

\section{LO QUE HABLAN LOS DISCURSOS DE GESTORES ESCOLARES SOBRE LA CALIDAD EDUCACIONAL}

\author{
WHAT THE SPEECHES OF SCHOOL MANAGERS SPEAK ABOUT \\ EDUCATIONAL QUALITY
}

\author{
Marcelo Siqueira Maia Vinagre MOCARZEL ${ }^{1}$ \\ Jorge Nassim Vieira NAJJAR ${ }^{2}$
}

RESUMO: Este trabalho busca investigar as construções acerca da qualidade educacional no discurso de quatro gestores escolares de escolas públicas e privadas do município de Niterói - RJ. Trata-se de uma pesquisa realizada a partir de dados coletados em uma dissertação de mestrado em educação, inserida no escopo do Núcleo de Estudos e Pesquisas em Gestão e Políticas Públicas em Educação, da Universidade Federal Fluminense. Através da interface entre Educação e Análise do Discurso, a pesquisa se iniciou com a investigação sobre os diferentes conceitos de qualidade no campo educacional e algumas de suas principais correntes teóricas. Buscou-se entender quais filiações ideológicas estão por trás dos discursos dos gestores escolares de quatro escolas consideradas de alta qualidade no município. Para isso foram realizadas entrevistas semiestruturadas e posteriormente interpretadas à luz da Análise de Discurso. Como resultados, obtivemos enunciados em que os sujeitos deslizam para diferentes papéis sociais e, assim, comprovam a polissemia do termo qualidade no âmbito educacional. O referencial teórico se baseou, sobretudo, em documentos de organismos nacionais e internacionais que tratam sobre a qualidade da educação, bem como nos principais estudiosos da escola francesa da Análise de Discurso.

PALAVRAS-CHAVE: Análise de discurso. Gestores educacionais. Qualidade.

RESUMEN:Este trabajo busca investigar las construcciones acerca de la calidad educativa en el discurso de cuatro gestores escolares de escuelas públicas y privadas del municipio de Niterói - RJ. Se trata de una investigación realizada a partir de datos recolectados en una disertación de maestría en educación, insertada en el ámbito del Núcleo de Estudios e Investigaciones en Gestión y Políticas Públicas en Educación, de la Universidad Federal Fluminense. A través de la interfaz entre Educación y Análisis del Discurso, la investigación se inició con el debate sobre los diferentes conceptos de calidad en el campo educativo y algunas de sus principales corrientes teóricas. Se buscó entender qué filiaciones ideológicas están detrás de los discursos de los gestores

${ }^{1}$ UNILASALLE, RJ - Brasil. Professor Substituto da UFF e Professor Assistente do. Pesquisador do NUGEPPE/UFF/CNPq. Doutorando em Comunicação (PUC-Rio) e Mestre em Educação (UFF). E-mail: marcelomocarzel@gmail.com

${ }^{2}$ UFF, RJ - Brasil. Professor Associado da UFF. Coordenador do NUGEPPE/UFF/CNPq. Doutor em Educação (USP). E-mail: jorgenajjar@gmail.com 
escolares de cuatro escuelas consideradas de alta calidad en el municipio. Para ello se realizaron entrevistas semiestructuradas y posteriormente interpretadas a la luz del Análisis de Discurso. Como resultados, obtuvimos enunciados en que los sujetos se deslizan hacia diferentes roles sociales y, así, comprueban la polisemia del concepto calidad en el ámbito educativo. El referencial teórico se basó sobre todo en documentos de organismos nacionales e internacionales que tratan sobre la calidad de la educación, así como en los principales estudiosos de la escuela francesa del Análisis de Discurso.

PALABRAS CLAVE: Análisis de discurso. Gestores educativos. Calidad.

ABSTRACT: This work investigates the constructions about the educational quality in the speech of four school managers from public and private schools in the city of Niteroi - RJ. This is a survey that started in a master's thesis, and was included in the scope of the researchs of NUGEPPE/UFF. Through the interface between education and Discourse Analysis, the research began among the different concepts of quality in education and some of its main theoretical currents. We wanted to understand what ideological affiliations are behind the speeches of school managers from four schools considered of having high quality. For that were conducted semi-structured interviews and then interpreted in with the tools of Discourse Analysis. As a result, we obtained stated that the subjects slide to different social roles and thus prove the polysemy of the term quality in the educational field. The theoretical framework was based mainly on documents of national and international organizations that deal with the quality of education as well as the leading scholars of the French School of Discourse Analysis.

KEYWORDS: Discourse analysis. School managers. Quality.

\section{Introdução}

A busca pela qualidade tornou-se, na contemporaneidade, um objetivo inerente a praticamente todas as esferas da vida social. Quando experimentamos produtos, serviços ou processos de qualidade, realizamos um comparativo com outras experiências, a fim de classificar e hierarquizar essas diferentes situações. Conseguimos, de maneira subjetiva, entender o que é qualidade ao a vivenciarmos, porém, a conceituação permanece sendo um desafio. E no campo educacional, esse desafio é ainda mais complexo.

Este artigo busca analisar discursos sobre a qualidade em educação e os diferentes sujeitos e imaginários construídos a partir do conceito. $\mathrm{Na}$ fala de gestores escolares, buscou-se o que seria educação de qualidade e quais as memórias evocadas nos discursos construídos sobre a educação de qualidade. A partir da utilização da Análise de Discurso (AD) como metodologia e de suas ferramentas, investigamos o que 
se fala e de onde se fala quando pensamos em qualidade em educação. O objeto de nossa pesquisa, portanto, são os discursos de quatro gestores escolares de quatro escolas do município de Niterói-RJ, duas públicas e duas privadas, que são consideradas referências pelo senso comum quando se fala em qualidade, sobretudo pelos resultados que atingem em avaliações de larga escala e índices externos. Trata-se de uma pesquisa que deriva de uma dissertação de mestrado de um dos autores e ganhou amplitude no Núcleo de Estudos e Pesquisas em Gestão e Políticas Públicas em Educação, da Universidade Federal Fluminense (NUGEPPE/UFF).

Um dos fatores que nos motivaram a desenvolver essa pesquisa foi a intensa presença da expressão "qualidade da educação" em diversos meios de comunicação, bem como nas falas de políticos, educadores, especialistas e até mesmo no senso comum. A Constituição Federal de 1988 traz a importância de se assegurar a qualidade educacional em seu texto, e outros documentos posteriores reforçam isso, como a Lei de Diretrizes e Bases da Educação Nacional, o Plano Nacional de Educação - que possui uma meta específica para esse objetivo - e que reverbera nas atuais discussões de recentes políticas públicas, como a Base Nacional Curricular Comum. Mais precisamente, entendemos que todas as políticas e programas educacionais de todas as esferas de governo reafirmam o desejo, em última instância, de melhorar a qualidade da educação, mesmo sabendo que nem todas contribuirão para isso. Mas que projeto de qualidade seria esse?

\section{Conceitos de qualidade em educação}

No Brasil, a qualidade educacional experimentou - e acreditamos que ainda experimenta - diferentes entendimentos. Em trabalho publicado anteriormente (MOCARZEL; TEIXEIRA; MORAES, 2016), foi apresentado um quadro sobre essa evolução do conceito, que resgatamos agora, a partir de Oliveira e Araújo:

De um ponto de vista histórico, na educação brasileira, três significados distintos de qualidade foram construídos e circularam simbólica e concretamente na sociedade: um primeiro, condicionado pela oferta limitada de oportunidades de escolarização; um segundo, relacionado à ideia de fluxo, definido como número de alunos que progridem ou não dentro de determinado sistema de ensino; e, finalmente, a ideia de qualidade associada à aferição de desempenho mediante testes em larga escala. (OLIVEIRA e ARAÚJO, 2005, p. 8) 
Os três momentos citados estão localizados temporalmente no século $\mathrm{XX}$. O primeiro conceito de qualidade, ligado essencialmente à questão do acesso, é decorrente da Revolução de 1930, quando há a reivindicação do acesso da população em geral à educação, encontrando no governo Vargas uma real possibilidade de efetivação. Até os anos 1970, há essa crescente demanda, buscando combater o elitismo que marca a educação brasileira. Sem deixarmos de lado as enormes disputas que dão o tom do processo de expansão, “[...] não se pode negar que esse momento representou uma conquista social, já que foi viabilizada a escolarização às classes populares" (CASTRO, 2009, p. 24).

Beisiegel (2006) chama de processo de democratização do ensino esse processo. Entendemos que se trata sim de um processo de democratização, uma vez que os dados comprovam a mudança de perfil da escola brasileira. A título de exemplo, Sposito (2002) mostra que, no estado de São Paulo, que à época possuía uma população de 7 milhões de habitantes, a matrícula no ensino primário fundamental era de pouco mais de 7,7\% em 1967. O que se tem hoje é um grande avanço, pois segundo o último Censo, no estado de São Paulo, 97,1\% das crianças entre 7 e 14 anos estão na escola (BRASIL, 2012). A democratização acaba por provocar mudanças paradigmáticas na educação, sobretudo em termos quantitativos. Escolas precisaram ser construídas e novas vagas para alunos e professores oferecidas, ainda que o elitismo pedagógico tenha permanecido. Essas mudanças acabam por gerar o segundo entendimento sobre qualidade, que visava à permanência dos alunos na escola e à ampliação do tempo de estudo, nos anos 1970 e 1980.

Oliveira e Araújo (2005) indicam que as desigualdades sociais ainda inviabilizam a efetivação de uma educação com qualidade para todos os cidadãos e que esta qualidade precisa servir aos alunos que à escola chegam. Para Beisiegel (2006, p. 120), “[...] é preciso aceitar a escola como ela existe. Isto não significa aceitá-la integralmente, com suas distorções, burocratizada, ritualizada, etc. Mas, aceitar, sobretudo, a qualidade da população que entrou na escola, que conquistou a escola". A permanência muito se liga à ideia de fluxo, em que a escola boa era aquela que reprovava, onde era difícil ser aprovado. Portanto, as escolas públicas e privadas passam a intensificar a reprovação, tratando o fluxo escolar como uma linha de montagem, que descarta aqueles que estão fora dos padrões. Esse imaginário permanece até hoje, mesmo que diversas pesquisas apontem justamente para o contrário, que altos índices de reprovação não representam uma melhor qualidade (MAINARDES, 2007). 
A terceira etapa tem sua origem nos anos 1990, com o grande foco avaliativo que o país passa a ter, seguindo uma tendência mundial. Com a implantação do Sistema de Avaliação da Educação Básica (Saeb), em 1990, do Exame Nacional do Ensino Médio (Enem), em 1998, e do Índice de Desenvolvimento da Educação Básica, (Ideb), em 2007, as políticas de avaliação passam a ser centrais na esfera nacional. Desse modo, o imaginário de qualidade passa a se basear nos resultados, nos índices, na performance dos alunos, escolas e redes. Este o terceiro e mais atual entendimento de qualidade da educação, ainda que os outros dois não estejam completamente superados.

Dourado, Oliveira e Santos (2007) enriquecem o quadro conceitual da qualidade em educação ao apresentarem, em documento produzido para o Ministério da Educação, as concepções dos organismos multilaterais. Escolhemos duas definições, de dois dos principais atores internacionais na área da educação: Unesco e OCDE - Organização para Cooperação e Desenvolvimento Econômico.

[...] a OCDE e a Unesco utilizam como paradigma, para aproximação da Qualidade da Educação, a relação insumos-processos-resultados. Desse modo, a Qualidade da Educação é definida envolvendo a relação entre os recursos materiais e humanos, bem como, a partir da relação que ocorre na escola e na sala de aula, ou seja, os processos ensino aprendizagem, os currículos, as expectativas de aprendizagem com relação a aprendizagem das crianças etc. (DOURADO, OLIVEIRA e SANTOS, 2007, p. 6)

Ainda segundo os autores, "[...] a Unesco ressalta, ainda, como critérios peculiares à avaliação da qualidade: a relevância, a pertinência, a equidade, a eficiência e a eficácia". (DOURADO, OLIVEIRA e SANTOS, 2007, p. 9). Por isso, concordamos quando afirmam que, do ponto de vista social, a educação é de qualidade quando contribui para a equidade e, do ponto de vista econômico, a qualidade refere-se à eficiência no uso de recursos. As duas perspectivas são relevantes para o alcance de objetivos de melhoria da educação.

É importante lembrar que a discussão sobre qualidade em educação não se encerra nos conceitos apresentados. Há importantes discussões que desdobram o tema, como a oposição entre qualidade e quantidade, a noção de qualidade total se opondo à de qualidade social, entre outras oposições. Um estudo mais detalhado dessas conceituações não caberia neste artigo, mas pode ser encontrado em Mocarzel (2013) e em outros autores. 


\section{Corpus da pesquisa e dispositivo de análise}

Como já exposto, esta pesquisa nasceu de nosso interesse pelos discursos acerca da qualidade. No ensino privado, a qualidade é utilizada como elemento de promoção das escolas, estabelecendo uma relação de competitividade com as demais. É utilizada para estimular a concorrência mercadológica, para atrair alunos e elevar o nome da instituição a um patamar de reconhecimento social. Ou seja, a qualidade passou a ser um serviço oferecido, um diferencial que algumas escolas teriam e outras não.

Os resultados dos alunos em avaliações externas são o mais poderoso elemento para que se atribua qualidade a uma escola: as instalações, a qualificação do corpo docente, a proposta pedagógica, a tradição, o material utilizado, o tipo de gestão, ficam em segundo plano diante dos resultados objetivos em provas como o Enem. E este modelo acaba por influenciar as escolas públicas também, que passam a ser consideradas de qualidade quando promovem o acesso dos alunos ao Ensino Superior ou pelos resultados no $\mathrm{Ideb}^{3}$.

Encerrar o corpus da pesquisa em algumas poucas páginas seria uma falsa pretensão. A elaboração do corpus da pesquisa pressupõe etapas, relacionadas diretamente com a análise. Orlandi (2010) afirma que “[...] a delimitação do corpus não segue critérios empíricos (positivistas), mas teóricos" (ORLANDI, 2010, p. 62). Ou seja, o corpus da pesquisa nasce a partir do caminho teórico escolhido e "[...] decidir o que faz parte do corpus já é decidir acerca de propriedades discursivas" (ORLANDI, 2010, p. 63).

A constituição do corpus depende então do referencial teórico utilizado. Orlandi (2010, p. 64) indica que "[...] a análise é um processo que começa pelo próprio estabelecimento do corpus e que se organiza face à natureza do material e à pergunta (ponto de vista) que o organiza". Ou seja, o corpus experimental nasce do pesquisador, de suas motivações, de suas perguntas e, por fim, de suas análises sobre o objeto de pesquisa. E ele só se efetiva quando a análise se efetiva, pois “[...] a noção de corpus corresponde ao recorte efetuado pelo analista na superfície discursiva a qual elabora uma seleção de formas, vistas como capazes de revelar o modo de delimitação de uma formação discursiva" (GRILLO, 2003). Se o corpus empírico corresponde às entrevistas, ou seja, a todo o material coletado, o corpus discursivo corresponde aos

3 Índice de Desenvolvimento da Educação Básica. 
recortes que faço, à escolha das sequências a serem analisadas e das marcas linguísticodiscursivas a serem interpretadas.

Realizamos as entrevistas a partir da escolha objetiva das escolas, baseada nas notas do Exame Nacional do Ensino Médio - Enem: escolas cujos alunos tiveram as maiores notas. Dentro do município de Niterói, escolhemos 4 gestores para entrevistar. Telefonamos para as escolas e averiguamos quem seria a pessoa responsável pela gestão pedagógica da mesma. Facilmente pudemos perceber quem era esse elemento ao chegar nas escolas, pois a dinâmica da mesma se organizava a partir deste gestor.

O nosso objeto de estudo foi o discurso de gestores escolares sobre a qualidade da educação. Tal discurso está marcado pelo contexto histórico, político, social, cultural e econômico no qual essas pessoas estão inseridas. As diferenças entre os entrevistados só servem para respaldar a multiplicidade de interpretações do discurso, que desliza de acordo com os sentidos pretendidos e os sentidos não pretendidos. Mesmo se a pesquisa tivesse sido realizada em uma mesma instituição, ou com pessoas com perfis semelhantes, a multiplicidade de sentidos seria inevitável.

Ainda nesta perspectiva, mesmo o não dito quer dizer, o silêncio comunica algo, os discursos construídos deixam seus rastros de filiação. Iremos buscar nas sequências discursivas as regularidades dos discursos, isto é, aquilo que se repete de diferentes formas, com diferentes significantes. "O corpus é construído a partir das categorias linguísticas que se quer investigar e o seu fechamento pressupõe que ele constitui uma amostra representativa da linguagem" (GRILLO, 2003). Ou seja, constituir o corpus é desenhar a pesquisa em três momentos: em seu planejamento, em sua realização e em sua análise posterior.

As sequências discursivas selecionadas trazem as regularidades a serem analisadas. O emparelhamento das sequências discursivas - recortes que fazemos ao longo da análise - busca rastrear as formações discursivas desses sujeitos, o sentido real da materialidade linguística e histórica e não o verdadeiro sentido (ORLANDI, 2010). Através do dispositivo de análise, constituiremos mais profundamente o caminho percorrido neste trabalho.

A construção do dispositivo de análise é essencial para que o pesquisador consiga de fato exercer seu papel. É a partir desta elaboração que a pesquisa se desenha e as perguntas passam a fazer sentido. Orlandi (2010, p. 26) nos mostra que ““c[...] a análise do discurso visa fazer compreender como os objetos simbólicos produzem 
sentidos, analisando assim os próprios gestos de interpretação". Então, a construção do dispositivo de análise, já é, em si, a análise.

Há uma distinção entre o dispositivo teórico da interpretação e o dispositivo analítico (ORLANDI, 2010). O dispositivo teórico é o que encapa o dispositivo analítico, isto é, é a pedra fundamental teórica de onde partem as análises empíricas. Ele, nada mais é do que o referencial utilizado, somado à metodologia; o caminho que percorremos até aqui e que levou, inclusive, à elaboração da pergunta. O mesmo dispositivo teórico pode levar a vários dispositivos analíticos.

Já o dispositivo analítico é particular; é uma individualização do dispositivo teórico. "O que define a forma do dispositivo analítico é a questão posta pelo analista, a natureza do material que analisa e a finalidade da análise" (ORLANDI, 2010, p. 27). A análise será feita por blocos: cada resposta estará ligada às sequências discursivas (SD) relacionadas, retiradas do texto transcrito. Sequência discursiva é entendida aqui como fragmento que diz algo sobre campo discursivo a que ela pertence. Assim, faremos relações entre as respostas dos gestores, analisando as recorrências nos discursos, principalmente.

A questão proposta é ampla. Foi pensada assim para que o entrevistado escolhesse o caminho de sua resposta com mais liberdade. Ao perguntar "O que é", deixamos claro que educação de qualidade era alguma coisa. Mas o final da questão, "para você", mostrava que existem diferentes lugares para se responder: você enquanto professor, enquanto gestor, enquanto cidadão, etc.

\section{As análises}

Ao iniciar o trabalho de escrita, optamos por ocultar o nome das escolas e dos gestores entrevistados. Esta ocultação foi uma escolha, mesmo tendo em mãos autorizações de todos os entrevistados para usar seus nomes e respectivas respostas nas análises. Optamos por ocultar o nome dos mesmos para que se tivesse mais liberdade nas análises.

Antes de apresentarmos as sequências discursivas (SD) ligadas à questão, é importante que apresentemos as condições de produção do discurso, o modo como identificamos, no panorama escolar, quem seria o gestor a ser entrevistado. Por se tratar do campo educacional, procuramos entrevistar gestores pedagógicos, ou seja, aqueles 
que têm poder de decisão sobre a pedagogia que se efetiva na escola. Se entrevistássemos gestores administrativos, a pesquisa ficaria, provavelmente, limitada.

Nas análises que se seguem, relacionamos as respostas aos gestores e grifamos nas respostas transcritas as partes que consideramos mais interessantes para uma interpretação mais aprofundada, sem desconsiderar os demais pontos colocados. Foi necessário fazer isso para que a pesquisa não se desviasse de seu objetivo principal, que é investigar as construções acerca do termo qualidade, quando utilizado no contexto educacional por gestores de escolas públicas e privadas do município de Niterói. A partir da questão "O que é educação de qualidade para você?", tivemos as seguintes respostas.

SD1/GESTOR A - Educação de qualidade é uma educação que oferece, ao final de uma trajetória, aí vamos pensar no ensino fundamental e médio, da educação básica, oferece ao aluno uma formação que dê a ele uma possibilidade de liberdade, de escolhas, emancipatória, o que eu vejo, e aí eu colocaria que o aluno né, no final tenha condições de se inserir na sociedade da maneira que ele escolher.

SD2/GESTOR B - Eu acho que você... é... ser democrático, mas é... exigindo que a filosofia e os objetivos sejam cumpridos, quer dizer, o professor tem o seu espaço, mas ele tem a sua delimitação dentro da filosofia e dentro dos objetivos do colégio. E além de tudo, eu só entendo qualidade quando há um respeito, se eu tiver que dizer alguma coisa para um professor eu não digo por trás, eu chamo e digo, aí eu posso falar por trás, que eu falo mesmo, não vou falar por trás, eu posso comentar, mas antes ele vai saber e também faço a mesma coisa com os outros...

SD3/GESTOR C - Eu acho que seria um número mínimo de reprovação, de evasão escolar, formar pessoas que realmente tivessem conteúdo, do ponto de vista da formação geral e da formação técnica, porque na verdade a gente trabalha com o aluno que sai daqui pro mercado de trabalho.

SD4/GESTOR D - Bom, educação de qualidade ela tem que unir ao mesmo tempo as questões acadêmicas, não há como fugir disso, essas questões relacionadas a conteúdos, ao aprendizado; só que além disso a escola também tem o seu papel de formação, então, vou dar alguns exemplos práticos aqui do nosso dia a dia. $O$ colégio, a instituição esse ano completa 175 anos e no meu entendimento essa tradição tem um peso muito positivo aqui pra nós, por exemplo, a gente cobra uniforme aqui de maneira rigorosa, porque não pela tradição do colégio, mas porque nós achamos que os alunos, ao entrarem aqui, têm que se sentirem iguais, então é quando o aluno está uniformizado, você não vai saber de quem, se ele é filho de médico, se ele é filho de um militar, se ele é filho de um gari, a mensagem que é dada a eles é que eles vão ser tratados de maneira 
igual e que eles devem saber conviver com as diferenças. Então a escola também é pra isso. Então a gente acha que uma das, dos pontos fortes do colégio é exatamente essa identidade que eles acabam tendo com a instituição, né...

SD5/GESTOR A - Só que a vivência de você ter aí essa vivência que eu tive, de ter um filho estudando há 17 anos, ele tem 17 anos e está aqui há 16 anos e 6 meses, então, muito tempo, então eu não consigo não considerar que a educação dele (não) seja marcada pela instituição na qual ele ficou ao longo desse tempo todo. E o que eu vejo como resultado, eu vejo uma possibilidade de liberdade de escolha da trajetória que ele vai ter daqui por diante, eu vejo um capital cultural que eu me sinto super orgulhosa...

Primeiramente, é importante lembrar que a pergunta é aberta, ampla, sem nenhum tipo de direcionamento específico da resposta. Qualquer coisa poderia ser respondida, dentro da limitação do tema. O único direcionamento está na preposição somada ao pronome "para você". Mas quem é você? Quem é o entrevistado? Seria ele o gestor? Seria ele o funcionário público? Seria ele um professor? Seria ele o sócio ou funcionário de uma empresa? Seria ele um cidadão?

Saber quem fala é o primeiro passo da análise. Se os quatro entrevistados foram tratados como gestores, inicialmente há deslocamentos desses sujeitos ao longo de suas falas para outros lugares discursivos. "Ao dizer, o sujeito significa em condições determinadas, impelido, de um lado, pela língua e, de outro, pelo mundo [...]”, afirma ORLANDI (2010, p. 53). É este sujeito determinado que buscamos encontrar; quem fala em cada momento?

Na SD1 destacamos, primeiramente, a construção "aí vamos pensar no ensino fundamental e médio, da educação básica”. Neste momento a gestora delimita seu espaço, evidenciando qual é a trajetória de que ela fala. Pensar na educação setorizada condiz com a realidade que constatamos nas quatro escolas: a seriação dos anos escolares. Esta é a trajetória considerada pela gestora, de onde ela fala. É um recorte prático, atrelado à sua vivência, uma vez que ela é gerente desses dois segmentos na escola.

Na mesma SD1, ela coloca que educação de qualidade é aquela que: "oferece ao aluno uma formação que dê a ele uma possibilidade de liberdade, de escolhas, emancipatória “[...]”. O foco desta resposta está no aluno, ou seja, para ela a qualidade pode ser vista no resultado final da trajetória do aluno. Uma educação de qualidade seria uma educação que leva à emancipação, conceito investigado por Santos: 
No direito romano clássico, a emancipatio era o ato jurídico pelo qual a criança era libertada do poder paternal (patria postestas). Mais tarde, passou a significar a libertação dos escravos e, num sentido ainda mais amplo, o levantamento de restrições legais sobre determinados grupos sociais (...) (SANTOS, 2009, p. 271)

Logo, emancipação sempre esteve relacionada à liberdade, à autonomia, à independência e, no caso da SD1, à liberdade de escolha. Significa dar ao aluno um aparato de ferramentas que o permita "se inserir na sociedade da maneira que ele escolher". Assim, este discurso coloca qualidade como um bem intangível, algo não aferível. E de onde vem este discurso? Seria da Filosofia? Como a entrevistada saiu de um pragmatismo extremo ao confinar todo o processo educacional em dois segmentos da educação e chegou a uma construção tão ampliada?

Pode-se considerar que neste momento o lugar do discurso fosse outro: não a gestora, mas a intelectual da educação, uma vez que a mesma disse que escreve artigos e participa de congressos; ou mesmo a representante do projeto político pedagógico de uma instituição de tradição, que tem princípios filosóficos resguardando sua prática. Ela deixa de lado o pragmatismo inerente ao seu cargo para tratar qualidade como algo intangível.

Na SD2 temos o seguinte trecho que responde a mesma pergunta: "Eu acho que você... é... ser democrático, mas é... exigindo que a filosofia e os objetivos sejam cumpridos". O respondente inicia sua fala com o direcionamento para o outro, como que construindo um manual do que seria qualidade. Mas imediatamente ele para, faz uma pausa, e retoma colocando o gestor como protagonista da efetivação da qualidade, aquele que deve exigir que a filosofia e os objetivos sejam cumpridos, por meio das atribuições do cargo.

Novamente ele fala desta posição discursiva de gestor: "o professor tem o seu espaço, mas ele tem a sua delimitação dentro da filosofia e dentro dos objetivos do colégio”. O sujeito do discurso reafirma o desafio que é a relação gestor - professor, em que o gestor é tido como um guardião dos princípios institucionais e, consequentemente, da qualidade que se faz presente na escola.

As conjunções adversativas "mas" demonstram um contraponto feito pelo gestor: ele opõe "ser democrático" ao verbo exigir; depois opõe "espaço" à “delimitação”. A SD2 produz o efeito de contraponto, mostrando que o gestor concentrou suas respostas na relação que estabelece com os professores, carregando a ideologia de um sujeito que se inscreve institucionalmente. 
Na SD3, a gestora pública traz à tona o discurso do poder público, recorrente nos meios de comunicação. Ao responder sobre o que é qualidade, ela prontamente coloca que "seria um número mínimo de reprovação, de evasão escolar, formar pessoas que realmente tivessem conteúdo, do ponto de vista da formação geral e da formação técnica”. A reprovação e a evasão não são problemas graves nas escolas particulares cujos gestores foram entrevistados. Porém, quando adentramos a realidade do ensino público, são dois dos principais problemas. Os dados do Relatório de Desenvolvimento 2012, divulgado pelo Pnud (Programa das Nações Unidas para o Desenvolvimento) mostram que o Brasil tem a maior taxa de evasão entre os cem países com maior IDH: $24,3 \%$ estudantes abandonam a escola. ${ }^{4}$

Um dos maiores desafios da política educacional nacional é elevar os resultados do Ideb das escolas e, para isso, os gestores são cobrados. Ao colocar estas duas prioridades na definição de qualidade, o sujeito que fala é o gestor que conhece a realidade da educação pública e como se dá essa cobrança. Só em terceiro lugar foi colocado que educação de qualidade seria "formar pessoas que realmente tivessem conteúdo, do ponto de vista da formação geral e da formação técnica”. Duas marcas linguísticas se destacam: a primeira é a utilização do advérbio de modo "realmente". Ao utilizar esta marca, a gestora diz que são formadas pessoas aparentemente com conteúdo, mas que na verdade não o têm. Ou seja, sob essas condições de produção do discurso, a gestora expôs sua visão sobre o que de fato acontece em relação à formação dos alunos.

Outra marca interessante é a distinção entre formação geral e técnica. Por se tratar de uma escola técnica, isto é, de uma escola que forma alunos através do ensino técnico, evidencia-se uma distinção entre as duas formas de ensino. Esta diferenciação fica marcada em outros momentos, ao citar os professores técnicos, ou as duas matrículas dos alunos. Assim, a formação técnica é retirada da formação geral, como se para se formar técnicos não fossem necessários elementos da formação geral e viceversa.

Na SD4 há uma recorrência dessa distinção: ao afirmar que "educação de qualidade ela tem que unir ao mesmo tempo as questões acadêmicas, não há como fugir disso, essas questões relacionadas a conteúdos, ao aprendizado, só que, além disso, a escola também tem o seu papel de formação”, este gestor novamente separa o

\footnotetext{
${ }^{4}$ Disponível em: <http://pnud.org.br/Noticia.aspx?id=3742>. Acesso em: 10 jan. 2016.
} 
aprendizado da formação. A marca "só que" reafirma essa oposição de instâncias que são vistas como separadas: "aprendizado" e "formação".

No trecho seguinte, o gestor fala pela instituição que dirige, em nome da sua tradição e utiliza um exemplo peculiar. "O colégio, a instituição esse ano completa 175 anos e no meu entendimento essa tradição tem um peso muito positivo aqui pra nós, por exemplo, a gente cobra uniforme aqui de maneira rigorosa, porque não pela tradição do colégio, mas porque nós achamos que os alunos, ao entrarem aqui, têm que se sentirem iguais”. Quem fala agora é o sujeito diretor de uma instituição pública de prestígio, que zela pela sua tradição. Segundo Santos:

A dimensão institucional dos espaços estruturais refere-se à organização da repetição na sociedade, isto é, as formas, padrões, procedimentos, aparatos ou esquemas que organizam o constante fluxo de relações sociais em sequências repetitivas, rotinizadas e normalizadas, por meio das quais os padrões de interação são desenvolvidos e "naturalizados" como normais, necessários, insubstituíveis e de senso comum. As instituições são instrumentos de controle do risco e da imprevisibilidade; é através delas que as sociedades estabilizam as expectativas dos indivíduos e grupos sociais. (SANTOS, 2009, p. 281)

O discurso institucional traz este apego à tradição, que demonstra segurança frente ao imprevisível. A tradição garante uma espécie de notório saber à instituição e, consequentemente, aos seus gestores. Por isso, o sujeito que fala, na verdade, é a escola, em resposta a um anseio da sociedade. Uma marca interessante é o verbo ter: "têm que se sentirem iguais". A igualdade não é uma opção: o uniforme determina isso, as diferenças entre eles são camufladas pelas roupas, em nome de um ambiente mais homogêneo, a marca "têm que" traz a obrigatoriedade.

O gestor escolheu o uniforme como metáfora da igualdade que existe na escola, por mais que os alunos sejam diferentes, como ele mesmo cita: "se ele é filho de médico, se ele é filho de um militar, se ele é filho de um gari”. Esta metáfora coloca a tradição como responsável principal pela igualdade que existe no ambiente escolar. Ou seja, o uniforme é, ao mesmo tempo, a manutenção da tradição, vista por ele como algo extremamente positivo; e, segundo ele, a garantia de igualdade, uma luta ainda inacabada nas escolas públicas brasileiras imersas no modelo liberal:

A palavra igualdade é chave na decifração da produção cultural que prepara a revolução francesa e a sucede. Mas é importante ressaltar que no pensamento liberal não se trata de preconizar uma sociedade na qual as desigualdades desaparecerão: trata-se de justificá-la sem 
colocar em xeque a tese da igualdade de oportunidades (...) (PATTO, 2010, p. 51)

É interessante ressaltar que dentro do modo de produção capitalista, a tendência da tradição é reafirmar as desigualdades, por mais que haja mobilidade social, como nos mostrou Patto. Assim, este discurso do GESTOR D é rico pela fragilidade do terreno em que ele se encontra, uma vez que a igualdade pode ser algo complexo. Seria igualdade a disciplinarização através do uniforme? Este uniforme possui uma força simbólica, pois ele obriga a ser igual. A tradição é elevada a um patamar diferenciado, portanto.

O gestor afirma que os alunos passam a ter um vínculo afetivo diferenciado com a escola, "essa identidade que eles acabam tendo com a instituição, né...". Esta marca "né” - advinda da oralidade - busca uma aprovação, uma concordância do interlocutor. Segundo ele, esta tradição acaba por gerar um caminho obrigatório de vínculo; não parte dos alunos, mas é a identidade institucional reafirmada simbolicamente que faz com que os alunos acabem tendo tal identificação.

Outra marca que despertou nossa atenção foi a utilização da locução "a gente”. Por mais que a pergunta tenha sido direcionada a ele, o GESTOR D fala aqui pela instituição, representando toda a crença de uma comunidade escolar, pelo menos de acordo como o seu ponto de vista. O sujeito institucional toma conta do discurso nas primeiras palavras. Os demais gestores também utilizaram marcas semelhantes: o GESTOR A utiliza a locução verbal "vamos pensar”, ocultando a primeira pessoa do plural; o GESTOR B utiliza o enunciado "Eu acho que você... é... ser democrático", levando novamente para o outro uma opinião que deveria ser guiada pelo "eu"; o GESTOR C utiliza o pronome "a gente", compartilhando com os demais membros da instituição a definição de qualidade. Todos os quatro gestores, quando perguntados sobre o que era educação de qualidade de acordo com a opinião pessoal, levaram seus discursos ao outro, demonstrando o quão imbricado é este terreno da qualidade e como as definições são abstratas e carentes de assertividade, como os autores colocam na citação a seguir.

\footnotetext{
Ainda que todos tenham uma noção e de algum modo saibam a que se referem quando desejam, propõem ou têm como objetivo um ensino de qualidade, uma escola de qualidade e uma educação de qualidade são ideias por demais abstratas, seus sentidos são polivalentes. É algo que ninguém pergunta o que é; sabe-se do que se trata, mas que não se sabe explicar. (SALLES e PASSOS, 2008, p. 293)
} 
Esta falta de definições mais concretas é o que possibilita o debate conceitual em torno da qualidade, que é proposto por este artigo. O descolamento do lugar discursivo para o outro reflete a falta de naturalidade com que os gestores lidam com a qualidade.

Ainda dentro da questão, retomamos o GESTOR A trazendo a SD5, em que a gerente pedagógica afirma que,

\begin{abstract}
a vivência de você ter aí essa vivência que eu tive, de ter um filho estudando há 17 anos, ele tem 17 anos e está aqui há 16 anos e 6 meses, então, muito tempo, então eu não consigo não considerar que a educação dele (não) seja marcada pela instituição na qual ele ficou ao longo desse tempo todo. E o que eu vejo como resultado, eu vejo uma possibilidade de liberdade de escolha da trajetória que ele vai ter daqui por diante, eu vejo um capital cultural que eu me sinto super orgulhosa...
\end{abstract}

De que lugar o sujeito produz seu discurso neste momento? Que memórias são evocadas? Entra em cena o sujeito mãe, que coloca a trajetória do seu filho como exemplo para uma trajetória de qualidade. Primeiramente, deixa claro que a instituição marca a educação recebida por ele. Em segundo, que o capital cultural, conceito trazido de Bourdieu (2009), que ele carrega produz nela o sentimento de orgulho, ou seja, há no sujeito mãe uma responsabilidade compartilhada com o sujeito gestora escolar pelo resultado do processo educacional do jovem. E terceiro que, para ela, o capital cultural só é fruto de duas instituições: família e escola.

\title{
Considerações finais
}

A metodologia escolhida, a $\mathrm{AD}$, nos auxiliou a interpretar as falas dos entrevistados e perceber quais formações discursivas estavam por trás das sequências recortadas e que posição o sujeito ocupava quando falava isto ou aquilo, ou seja, de que lugar ele falava, que memória discursiva se fazia presente, qual filiação ideológica era dita ou era silenciada.

Nossa intenção não foi, em momento algum, chegar ao conceito definitivo de qualidade ou afirmar o que pensam todos os gestores a partir da fala dos quatro entrevistados. Porém, uma constatação nos arriscamos a fazer: não deve existir um modelo único de qualidade, mas um conjunto de boas práticas que possibilitem cada 
instituição a atingir o seu ideal de qualidade. Vemos qualidade como uma utopia, algo radicalmente melhor do que o que temos hoje.

E por utopia entendemos a exploração, através da imaginação, de novas possibilidades humanas e novas formas de vontade, e a oposição da imaginação à necessidade do que existe, só porque existe, em nome de algo radicalmente melhor por que vale a pena lutar e a que a humanidade tem direito. (SANTOS, 2009, p. 331)

Para Santos, utopia é a conjunção de novas possibilidades e novas formas de vontade. A qualidade deve ser a busca incessante de novas e melhores maneiras de educar: seja melhorando a estrutura física da escola, seja transformando o modelo de gestão, seja qualificando os professores, seja reestruturando a sistemática de ensino; a qualidade sempre está a serviço de um projeto de sociedade. Então que qualidade/sociedade queremos ter?

O homem é marcado pelo contexto em que se insere, pela história, pela ideologia, pelas memórias, pelos discursos, pelas suas relações sociais e relações com a natureza. Tais relações sociais são constituídas pela memória, que alimenta a história e “procura salvar o passado para servir ao presente e futuro" (LE GOFF, 2003, p. 471). É preciso que esta memória seja motor da libertação e não da opressão. Mas, muitas vezes, as filiações ideológicas trazem discursos de opressão e manutenção da ordem vigente, o que inibe qualquer transformação que busque uma nova qualidade para a educação.

Ao longo das entrevistas, os sujeitos-gestores ocuparam posições discursivas variadas. O GESTOR A, por exemplo, trouxe discursos do sujeito-mãe, do sujeitointelectual, do sujeito-gerente pedagógico. Estas diferentes posições discursivas nos levam a concluir que o sujeito transita através de diferentes formações, carregando uma incompletude que o faz buscar em outro lugar discursivo as respostas. Há um conflito entre o que se pode falar e o que se deve falar, na medida em que se ocupa determinado cargo. Para falar de certas delicadezas do processo educacional, é preciso, muitas vezes, tirar sua roupa de gestor e vestir outra. Tais deslizamentos são reflexos das filiações ideológicas que significam nos discursos dos sujeitos.

A ideologia faz parte do real: sem ela não há sujeito, não há transformação e nem conhecimento. Pêcheux (2009, p. 233) afirma que "não se rompe jamais com a ideologia em geral, mas sempre com esta ou com aquela formação ideológica, inscrita histórico-materialmente no conjunto complexo das formações ideológicas de uma 
formação social dada". Ou seja, ao se deslocar, o sujeito rompe com uma filiação ideológica, mas se filia a outra; não existe discurso livre de ideologia.

Um dado interessante foi a constante significação do outro nas respostas. Marcas como "a gente", "você", "nós", serviram de estratégia para responder perguntas direcionadas. Santos (2009), baseado nas ideias de Said e Tucker, nos mostra que muitas vezes se usa o outro quando se é incapaz de representar a si próprio.

A diferenciação desigual [...] opera mediante a criação da alteridade, da agregação da identidade e do exercício da diferença na base de critérios mais ou menos deterministas [...]. Ora, como Edward Said (1985) mostrou eloquentemente, os que são definidos como o Outro são também definidos como incapazes de se definirem e representarem a si próprios. (SANTOS, 2009, p. 287)

Pini (2009) aponta que a associação entre Análise do Discurso e educação pode ajudar a combater a colonização simbólica que as escolas sofrem, realizada pela ideologia neoliberal que se amplia e se naturaliza no campo educacional. Se as práticas educativas são práticas discursivas, cabe ao gestor compreender isso e entender que seus discursos são marcados por formações ideológicas. Quando o assunto é qualidade, fica ainda mais nítido o tipo de filiação que cada discurso traz. A filiação ao discurso da empresa capitalista, a filiação ao discurso governamental, a filiação ao discurso da categoria profissional, a filiação ao discurso institucional (escolar). Cada uma presume um tipo de qualidade, cada uma foi identificada nas falas dos gestores escolares, em diferentes momentos, através de diferentes sujeitos.

O individualismo característico do mundo contemporâneo dominou discursos e práticas. As pessoas desejam, através da educação, a inserção no mercado, o exercício da cidadania e a felicidade no campo pessoal, e isto se reflete no discurso dos gestores. O que eles esperam de uma educação de qualidade é o que a sociedade cobra da escola, dos professores e dos gestores. Encontramos uma carência de discursos atrelando qualidade à transformação social. Parece que a sociedade projetada nos discursos deseja aparar arestas e não uma mudança radical nas formas de poder e organização da sociedade. O exercício da emancipação deve ser conjunto, "tem de se integrar numa constelação de práticas e de relações emancipatórias" (SANTOS, 2009, p. 269). Emancipar-se sozinho não é emancipar-se. Esta emancipação precisa ser tão relacional como o poder contra o qual ela se insurge. (SANTOS, 2009) A qualidade precisa estar a serviço da articulação de diferentes relações emancipatórias para que de fato seja 
qualidade, sinônimo de melhoria. Uma educação que só dá ferramentas ao aluno para que ele reproduza e reforce as desigualdades sociais não é educação.

\section{REFERENCIAS}

BEISEGEL, C. R. A qualidade do ensino na escola pública. Brasília: Liber Livro, 2005 .

BOURDIEU, P. A economia das trocas simbólicas. São Paulo: Perspectiva, 2009.

CASTRO, A. M. A qualidade da educação básica e a gestão da escola: In: FRANÇA, M.; BEZERRA, M. C. (orgs.). Política educacional: gestão e qualidade do ensino. Brasília: Liber Livro, 2009.

DOURADO, L. F; OLIVEIRA, J. F.; SANTOS, C. A. A qualidade da educação: conceitos e definições. Brasília: INEP/MEC, 2007.

GRILLO, S. Função dos gêneros e metodologia na constituição do corpus em análise do discurso. Estudos Linguísticos. Taubaté: GEL, v.32, 2003.

LE GOFF, J. História e memória. Campinas, SP: Editora da Unicamp, 2003.

MAINARDES, J. Reinterpretando os ciclos de aprendizagem. São Paulo: Cortez, 2007.

MOCARZEL, M. Os caminhos da qualidade na educação: análise de discurso de gestores escolares. 2013. 125 f. Dissertação de Mestrado (Educação). Niterói, RJ: Universidade Federal Fluminense, 20 fev. 2013.

MOCARZEL, M.; TEIXEIRA, L.; MORAES, V. Perspectivas teóricas sobre a qualidade educacional e sua relação com direito à educação. In: Anais do II Seminário do Grupo de Estudos e Pesquisas em Política e Avaliação Educacional. Campinas, FE/Unicamp, v. 1,. p. 297-311, 2016.

OLIVEIRA, R. P.; ARAÚJO, G. C. Qualidade do ensino: uma nova dimensão da luta pelo direito à educação. Revista Brasileira de Educação. n. 28 p.5-23, jan./fev./mar./abr. 2005.

ORLANDI, E. Análise de discurso: princípios e procedimentos. Campinas, SP: Pontes, 2010.

PATTO, M. H. S. A produção do fracasso escolar: histórias de submissão e rebeldia. São Paulo: Casa do Psicólogo, 2010.

PÊCHEUX, M. Semântica e discurso: uma crítica à afirmação do óbvio. Campinas, SP: Editora da Unicamp, 2009. 
PINI, M. (org.). Discurso y educación: herramientas para el análisis crítico. San Martín: UNSAN, 2009.

SALLES, L. C. e PASSOS, G. As aparências não enganam: representações de qualidade suscitadas pelos prédios escolares. Revista Brasileira de Educação, v. 13 n. 38, maio/ago. 2008

SANTOS, B. S. A crítica da razão indolente: contra o desperdício da experiência. São Paulo: Cortez, 2009.

SPOSITO, M. O povo vai à escola: a luta popular pela expansão do ensino público em São Paulo. São Paulo: Edições Loyola, 2002.

\section{Como referenciar este artigo}

MOCARZEL, Marcelo Siqueira Maia Vinagre.; NAJJAR, Jorge Nassim Vieira. O que falam os discursos de gestores escolares sobre a qualidade educacional. Revista IberoAmericana de Estudos em Educação, Araraquara, v. 12, n. 3, p. 1820-1838, julset/2017. Disponível em: <http://dx.doi.org/10.21723/riaee.v12.n.3.2017.8770>. EISSN: 1982-5587.

Submetido em: 10/07/2016

Aprovação final em: 02/07/2017 